\title{
Hallo, Nachbar!
}

\section{Erhard Taverna}

Dr. med., Mitglied der Redaktion

«Nachbarschaften sind ein Welttheater im Kleinformat» oder «Nachbarn sind Prüfungsaufgaben, die uns das Leben stellt». Zwei Zitate von vielen. Wie bei jeder

\section{In der Galerie der Nachbarschaftsdinge geht es um das Umsorgen und Streiten.}

Prüfung kann man durchfallen oder bestehen. Den täglichen Tanz um Nähe und Distanz thematisiert eine Ausstellung des Vögele Kultur Zentrums in Pfäffikon SZ. Eine vielschichtige Angelegenheit mit Konfliktpotential und Wohlbefinden, wie eine Gruppe von Stachelschweinen am Anfang des Rundgangs vor Augen führt. Der Philosoph Arthur Schopenhauer verglich das Zusammenleben mit den ausgestellten Exemplaren. Zu viel Abstand erzeugt keine Nestwärme, bei zu grosser Nähe verletzen die Stacheln. Eine Gratwanderung des distanzierten Miteinanders, die frustrieren und beglücken kann. Fünf Bereiche thematisieren die komplexe Geschichte des Wohnens. In der Mitte ein Forum mit Tischen und Stühlen, stellvertretend für viele Gemeinschaftsräume. Eine grosse Pinwand steht für Angebote und Mitteilungen zur Ver- fügung. Viele Flyers und Broschüren zeigen originelle Ideen zur Nachbarschaftshilfe, Modelle für solidarisches Zusammenleben, vom Einkaufen, Vorlesen und gemeinsamen Mittagstisch bis zum Tausch «Zvieri gegen Gesellschaft». Gleich nebenan demonstriert der Kurzfilm Neighbours von Norman McLaren ein Kontrastprogramm, in dem zuvor friedliche Nachbarn einander aus nichtigem Grund mit Zaunlatten traktieren. In der Galerie der Nachbarschaftsdinge geht es um das Umsorgen und Streiten, und natürlich auch um ein Problemquartier, um den Alltag in herausfordernden Wohngebieten, wo sich Sozialhilfeempfänger und ver-

\section{Mit Geld lässt sich Distanz kaufen.}

schiedene Kulturen auf engem Raum zusammendrängen. Der Soziologe Sebastian Kurtenbach sieht in Köln-Chorweiler die Broken-Windows-Theorie bestätigt. Gleiches findet er auch in Suhr, Pratteln, Grenchen oder Biel. Je verwahrloster eine Gegend ist, desto gleichgültiger gehen Menschen mit der Umwelt und miteinander um. Andererseits gilt, je geringer die wahrgenommene soziale Distanz, desto besser das

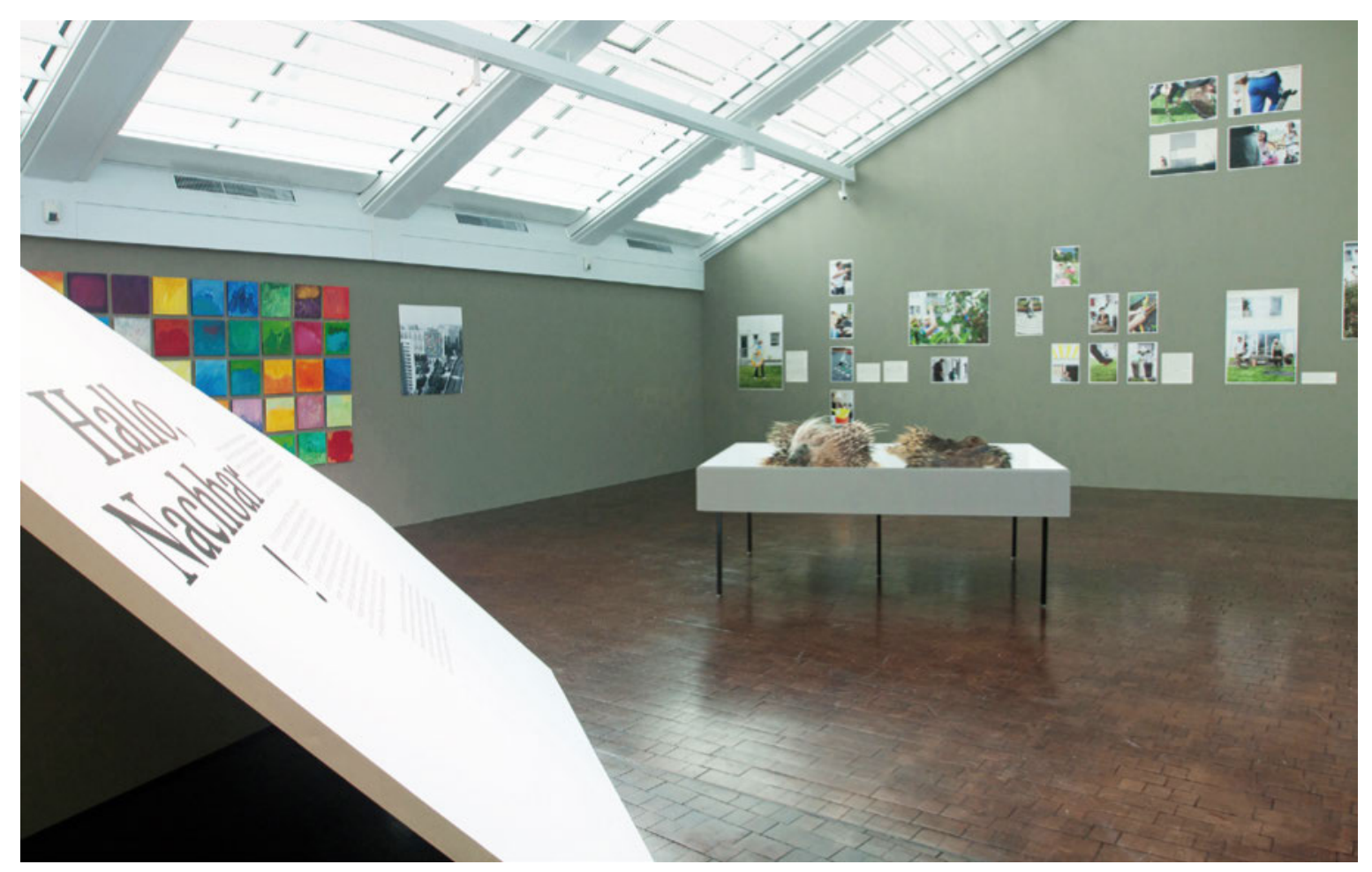




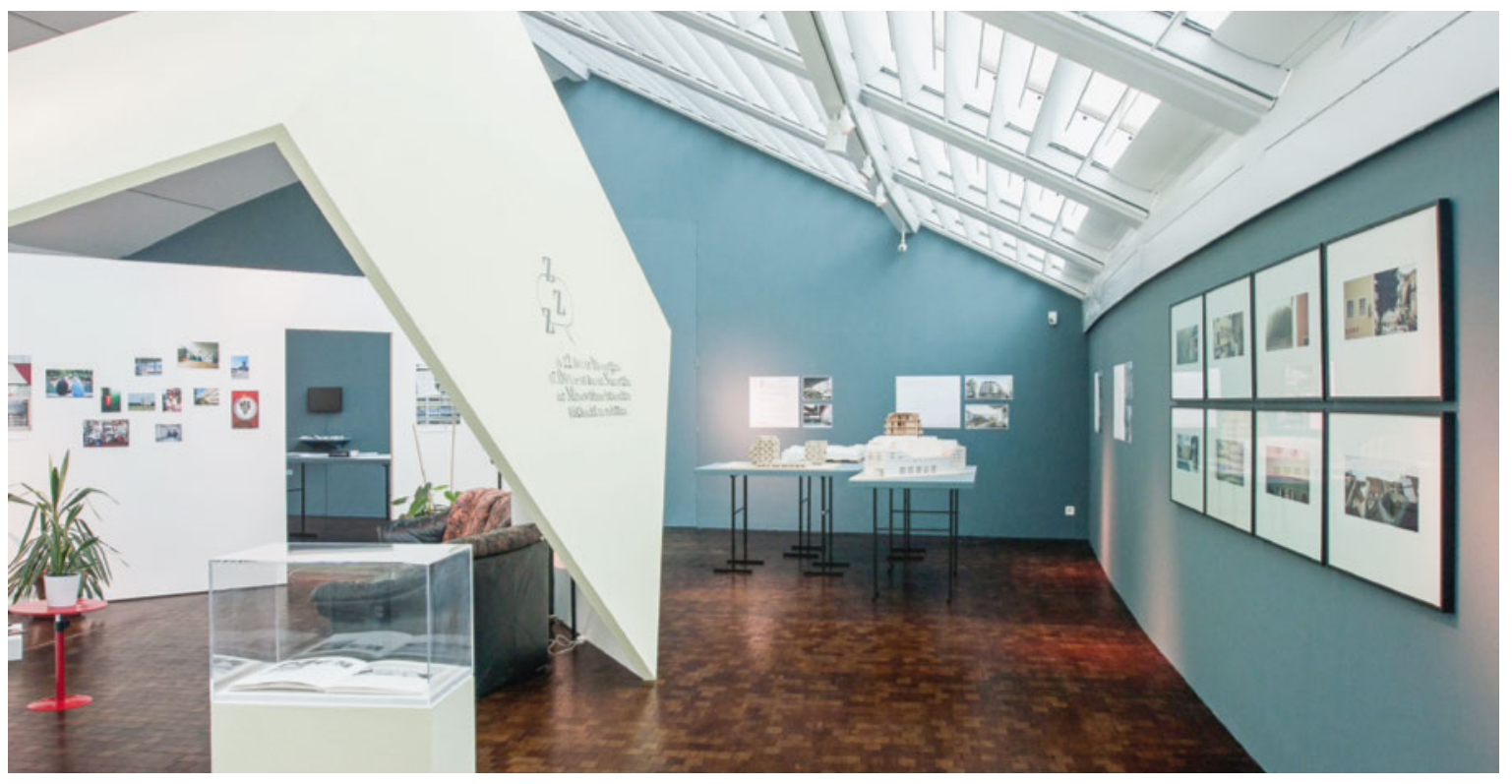

nachbarschaftliche Verhältnis, denn Gleich und Gleich gesellt sich gern. Eine starke Nachbarschaft, die abweichendes Verhalten, wie Vandalismus oder Kriminalität sanktioniert, ist auch eine sichere Nachbarschaft. Die Ausstellung präsentiert aktuelle Schweizer Beispiele

\section{Das Leben der anderen bleibt eine Quelle von} Phantasien, von Ängsten und Neid, von Neugier und Spionage.

von Wohnbauprojekten, die maximale Nutzung, Privatheit und Kontaktmöglichkeiten, Offenheit nach aussen und Altersdurchmischung zu vereinigen suchen. Ein Farbatlas der Stadt Zürich erinnert daran, dass die Farben der Fassaden viel zur Stimmung einer Strasse oder eines Quartiers beitragen. Wie immer, wenn das Kulturzentrum ein Thema anschaulich macht, sind es die vielen Details, die oft spielerisch für erhellende Einblicke sorgen. Etwa die Wohnungsgeräusche, die man beim Klingeln durch die Türen wahrnimmt, Pflanzen, die man beim Giessen in fremden Wohnungen vorfindet, voyeuristische Blicke als Kunstwerke, Tatort-Häuser aus Einfamilienhaus-Siedlungen oder digitale Nachbarschaften, die on demand funktionieren. Menschen im öffentlichen Raum verhalten sich noch einmal anders. Wo Menschen im Verkehr eng zusammenrücken müssen, fehlen die schützenden Wände. Wenn Körper sich berühren, kann man als Letztes nur noch den Blickkontakt vermeiden. Mit Geld lässt sich Distanz kaufen. Im Erstklasseabteil der Bahn, im privaten Einbettzimmer des Spitals, im EFH mit Umschwung, in der Loft mit Dachterrasse. Nachbarschaft, ob fern oder nah, gibt es immer. Das Leben der anderen bleibt eine Quelle von Phantasien, von Ängsten und Neid, von
Neugier und Spionage. Daran erinnern Filme wie Mon Oncle oder Breakfast at Tiffany's und Kino-Sonntage mit Filmen wie Das Fenster zum Hof von Alfred Hitchcock, Life in Paradise - Illegale in der Nachbarschaft von Roman Vital und Ein Mann namens Ove von Hannes Holm. Das reichhaltige Begleitprogramm bietet zudem Führungen, die das komplexe Thema vertiefen und verstehen helfen. Den zahlreichen Mitarbeitenden ist wieder einmal eine eindrückliche, unbedingt sehenswerte Ausstellung gelungen.

\section{Bildnachweis}

Ausstellungsansicht: Vögele Kultur Zentrum, «Hallo, Nachbar! Der tägliche Tanz um Nähe und Distanz», Foto: Nadia Sambuco Key Visual: «Hallo, Nachbar! Der tägliche Tanz um Nähe und Distanz», Die Ausstellung zu Nachbarschaften

\section{Ausstellung «Hallo, Nachbar!» \\ Vögele Kultur Zentrum, Pfäffikon SZ \\ 26.11.2017-25.3.2018 \\ www.voegelekultur.ch}

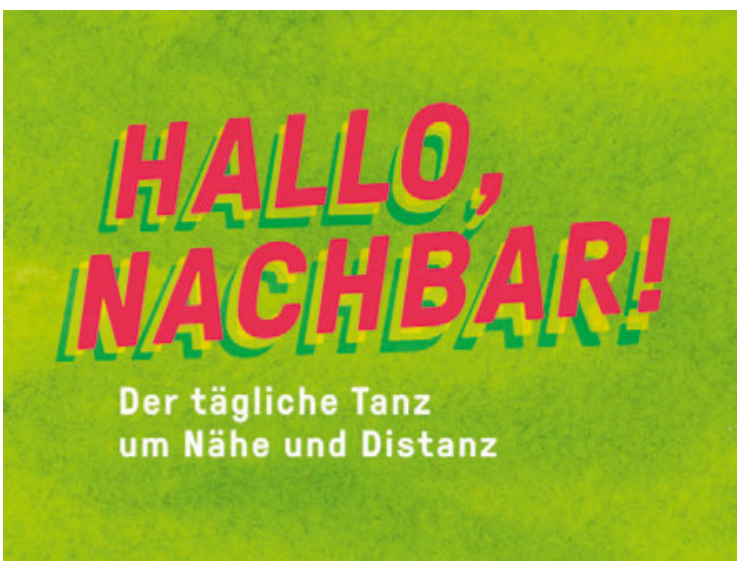

